\title{
Notas sobre o teatro brasileiro: uma perspectiva descolonial
}

\author{
Notes on Brazilian theater: \\ a decolonial gaze
}

\section{Elisa Belém}

Elisa Belém

Pós-doutora em Artes pela Escola de Belas Artes da Universidade Federal de Minas Gerais (UFMG, com o suporte da bolsa PMPD Fapemig/ Capes 10/2013. Doutora em Artes da Cena pelo

Instituto de Artes da Universidade Estadual de Campinas (Unicamp), com o suporte da bolsa FAPESP. Mestre em Teatro (Estudos da Performance) pela Royal Holloway, University of London

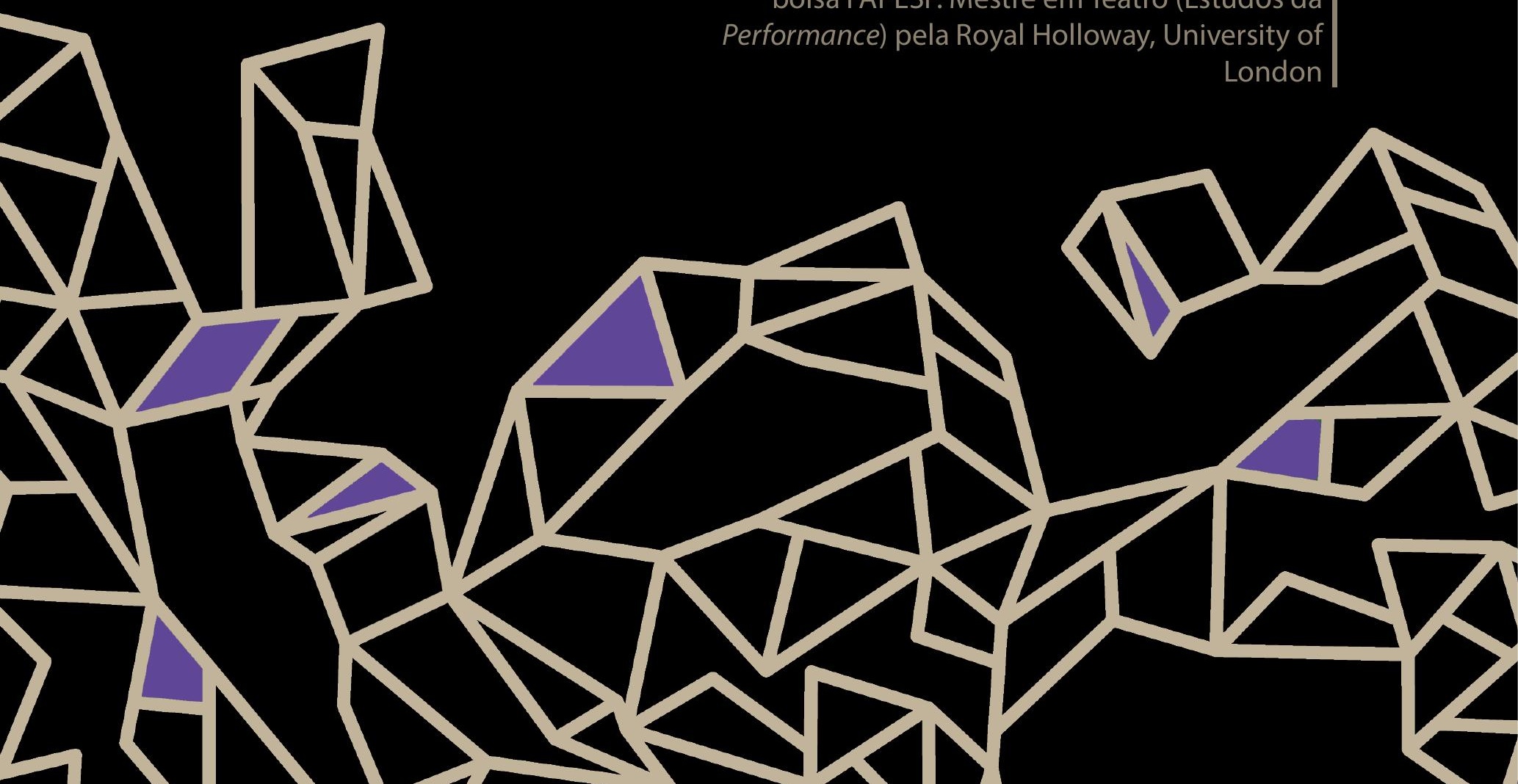




\section{Resumo}

O artigo apresenta questões relativas ao teatro brasileiro. Defendendo um pensamento fronteiriço, uma descolonização do pensamento e da subjetividade, discute-se a importância da valorização da literatura e das artes cênicas como saberes outros, cujas práticas instruem a produção de conhecimento teórico. Indica-se que a necessidade de criar pode servir como parâmetro para refletir sobre a presença simultânea da brincadeira e da representação, em diversas manifestações performativas e cênicas brasileiras.

Palavras-chave: Descolonial, América Latina, Colonialidade, Teatro.

\section{Abstract}

This paper focuses on issues related to Brazilian theater. Advocating a border thinking and a decolonization of thought and subjectivity, we discuss the importance of recognizing the value of literature and performing arts as other forms of knowledge, whose practices create theoretical knowledge. We propose that the need to create can be a parameter for reflecting on the simultaneous occurrence of playing and acting in many Brazilian cultural and theatrical performances.

Keywords: Decolonial, Latin America, Coloniality, Theater.

A discussão sobre o teatro brasileiro ainda é de ordem minoritária no panorama internacional. Visto nesse contexto, parece ocupar um lugar "subalterno". Segundo Mignolo (2003, p. 259), "subalterno" não constituí uma categoria, mas sim uma perspectiva. Para esse teórico, "(...) a atual versão dos estudos subalternos da América Latina está dentro do arcabouço delineado por Darcy Ribeiro, com sua visão da colonização como uma subalternização de povos e culturas" .

A atitude de grupos teatrais brasileiros, ao assumirem a elaboração de treinamentos próprios e também a autoria de seus espetáculos, parece colaborar para inverter a posição "subalterna". Suas práticas como um todo, ao cruzarem aspectos do local, com outros, nacionais e internacionais (intra e interculturais), valorizam as pró- 
prias sensibilidades e capacidades críticas de articulação de saberes. É recuperada uma liberdade, a qual a história primeiramente negou, atuando como uma forma de descolonização. Mignolo (2003, p. 259) esclarece que "os estudos subaltenos introduziram o nível de ações afetivas como um tipo diferente de racionalidade". As artes da cena trabalham exatamente com práticas que privilegiam as ações afetivas contribuindo para que o próprio indivíduo ou a sociedade reconheça aquilo que cerceia a expressão e comunicação humana, ou seja, possíveis silenciamentos.

O teatro realizado no Brasil hoje - o trabalho com a criação coletiva, o processo colaborativo, a dramaturgia de grupo e os solos, mostram a reinvenção de estilos, escolas teatrais e da própria dramaturgia estudada nas escolas brasileiras, prioritariamente a partir da história do teatro e do drama europeus. É preciso lembrar que o estabelecimento do teatro no Brasil advém da época da colonização. A produção intelectual sobre o teatro pareceu seguir a mesma lógica durante muito tempo: "O teatro foi o espaço de abordagem de muitos problemas, tanto do ponto de vista do dominado como do dominador. No entanto, os desempenhos têm sido registrados até hoje segundo a versão do dominador" (CAFEZEIRO; GADELHA, 1996, p.11).

Sendo assim, é preciso resgatar, ou mesmo, produzir um novo "olhar de dentro" da cultura brasileira para pensar questões geradas pelas encenações das peças teatrais, em seus gêneros variados e as práticas de grupos das diversas regiões do país - suas escolhas e alternativas para tornar a "letra", "carne" ou a "carne", "letra"; para colocar o corpo em ação e para construir linhas de ações psicofísicas. Essas práticas podem ser consideradas à luz do pensamento descolonial e daquilo que Boaventura de Sousa Santos (2004) nomeou como um anticolonialismo, subvertendo o primeiro propósito do estabelecimento do teatro no Brasil pelos colonizadores e a colonialidade do poder, do saber e do ser remanescentes.

É interessante verificar o caminho da colonialidade do conhecimento, que privilegiou a escrita e algumas línguas que se originaram do latim e que prevaleciam na Europa moderna. Consequentemente, houve uma desvalorização de saberes alheios a essa palheta de línguas e conhecimentos instituídos. O privilégio de algumas línguas e a produção do conhecimento aca- 
dêmico nos países europeus é destacado por Wallerstein, (1996:3) (Apud: MIGNOLO, 2003, p. 262-263):

Pelo menos $95 \%$ de todos os estudiosos e de todo o conhecimento acadêmico no período de 1850 a 1914, e provavelmente até 1945, origina-se de cinco países: França, Grã-Bretanha, as Alemanhas, as Itálias e os Estados Unidos. Há uma produção insignificante em outros lugares, mas basicamente não só o pesquisador vem de um dos cinco países, mas quase toda a produção de conhecimento pela maioria dos estudiosos é sobre seu próprio país. Assim sendo, a maior parte do conhecimento diz respeito a esses cinco países.

Dessa forma, a maior parte da produção acadêmica se originava e versava sobre cinco países, por meio de quatro línguas, das quais três tinham o mesmo prestígio e influência - inglês, francês e alemão.

Para Wallerstein (Ibid.), o fato referido levou ao aparecimento do campo da Antropologia e dos Estudos Orientais, que se referiam a países colonizados pela Europa. Mais tarde, constituiram-se também os campos de Estudos Pré-colombianos, Mesoamericanos e Andinos, assim como, os Estudos Latino-americanos. Richard Morse problematiza a constituição do último, argumentando, de acordo com Mignolo (2003, p. 268), que “(...) situava a América Latina como um campo de estudos, mas não como um lugar onde se produziam teorias e ideias". Somam-se a isso, as dificuldades enfrentadas para a realização da atividade de pesquisa na América Latina:

A corrupção governamental e a falta de informação, de livros ou tecnologia, são outros obstáculos para a pesquisa "bem-sucedida", como se poderia fazer em Paris, Bordeaux, Nova York ou Durham. O fato é, então, que os cânones epistemológicos não se dissociam da organização social e econômica. (Ibid., p. 287)

Essa linha de pensamento, versada pelos Estudos Subalternos, aponta para a necessidade da descolonização intelectual, na contramão da subalternização do conhecimento, levando à constituição de um pensamento liminar ${ }^{1}$.

1 Para Mignolo (2003, p. 410), “O 'pensamento liminar' com toda a sua complexidade (geo-histórica, sexual, racial, nacional, diaspórica, de exílio etc), é uma forma de pensamento que emerge como reação às condições de vida cotidiana criadas pela globalização econômica e pelas novas faces da diferença colonial." 
É claro que as atividades de pesquisa e conhecimento acadêmico se ampliaram no mundo, desde 1945 até os dias atuais. De acordo com Mignolo, o número de pesquisadores falantes do espanhol aumentou significativamente e, desde 1994, essa língua tornou-se uma das três mais privilegiadas. No entanto, ainda se mostra necessário o estímulo à produção intelectual a partir das questões próprias às culturas, por pessoas nascidas em cada um dos países. Isso porque, a questão da colonização e dos processos de descolonização refletidos nos hábitos e nas relações sociais são vivenciados pelos corpos dos indivíduos. Esta questão e os processos subsequentes, se mostram mais nítidos em casos envolvendo racismo, desigualdades econômicas e sociais de toda ordem. No entanto, não parece haver corpo ou indivíduo imune aos efeitos da colonização e da descolonização nas culturas que sofreram esses processos. Além disso, aparecem também outras problemáticas, como a desvalorização da atividade intelectual, artística e de ensino nos países em desenvolvimento.

A questão da desvalorização da atividade artística e intelectual é bastante complexa. Como mostra Mignolo (2003, p. 304), não há um modo único de "(...) produzir, transplantar e transformar o conhecimento". E isso se aplica também à esfera acadêmica, já que esta possui um modo de "linguajamento" que excluí outros. Conforme o autor, isso leva, por exemplo, à crença de que a literatura não constitui conhecimento sério:

Minha discussão visa criar, através do pensamento liminar (isto é, pensamento situado entre as ciências humanas e a literatura) um arcabouço no qual a prática literária não seja concebida como objeto de estudo (estético, linguístico ou sociológico), mas como produção de conhecimento teórico; não como "representação" de algo, sociedade ou ideias, mas como reflexão à sua própria moda sobre problemas de interesse humano e histórico. (lbid., p. 305)

A discussão de Mignolo se parece bastante com a reflexão proposta por Sperber (2009, p. 82) ao pensar sobre a prática literária no Brasil. Sperber mostra que, no ocidente, o pensamento obedece à lógica da identidade, que é excludente e que tende à seriedade. Segundo a autora, o enunciado sério, entendido como objetivo e correspondente à realidade, é visto como mais importante e digno de ser investido com o valor de verdade do que a represen- 
tação ficcional. Esse fato levaria à desvalorização da representação ficcional, passada a ver como de segundo grau e categoria. Consequentemente, o pensamento manifestado pela via ficcional seria desqualificado ou relativizado.

À questão referida, soma-se:

As culturas do saber acadêmico são colocadas em termos de legados textuais nacionais, pois é nos textos e por eles que se estrutura o sistema educacional, na moderna Europa Ocidental (a Europa de Hegel e Fichte) e que se articula, acondiciona, transmite e exporta a ciência. (MIGNOLO, 2003, p. 355-356)

O fato leva a crer que há, portanto, uma desvalorização tanto da oralidade quanto de outras formas de saberes que não são registrados como texto escrito, como no caso das artes e, particularmente, das artes da cena, que se dão como saberes das práticas corporais.

Pode-se comparar também a questão percebida na discussão sobre a literatura, a respeito de sua desvalorização, com as artes. A hipótese de Mignolo sobre a prática literária pode ser transposta para os estudos sobre as artes cênicas. Apropriando da hipótese, podemos pensar também que a prática cênica não seja concebida como "objeto de estudo (estético, linguístico ou sociológico), mas como produção de conhecimento teórico; não como "representação" de algo, sociedade ou ideias, mas como reflexão à sua própria moda sobre problemas de interesse humano e histórico" (Ibid., p. 305). Essa perspectiva poderia ser considerada no processo de ensino e aprendizagem sobre o teatro brasileiro.

Nesse sentido, seria necessário estudar, de forma mais aprofundada, as práticas corporais e de criação cênica, nas salas de ensaio e no ato de seus acontecimentos ao vivo, que podem conduzir à produção de conhecimento teórico. Para Stuart Hall (2013, p. 14):

A teoria é uma tentativa de solucionar problemas políticos e estratégicos; não uma elaboração a partir deles. A teoria é uma tentativa de saber algo que, por sua vez, leva a um novo ponto de partida em um processo inacabado de indagação e descoberta; não é um sistema que precisa ser acabado, útil na produção de conhecimento. 
Sendo assim, é importante considerar o trabalho teórico como um "jogo agonístico" (HALL, 2013, p. 13), que pressupõe a "(...) subjetividade como ponto de partida de qualquer discurso" (Ibid., p. 17). Talvez possamos considerar que o pensamento teórico possa ser gerado a partir de diversas práticas e linguagens, além da linguagem discursiva verbal. A esse debate, somam-se pensamentos de Mignolo (2011, p. xxiv): "É a partir do corpo, não da mente, que questões surgem e que respostas são investigadas. $O$ que chama para pensar é o corpo, não a mente [...]" . E ainda: "Quais são as conexões entre seu corpo, bio-graficamente e geo-historicamente localizado na matriz colonial do poder, e as questões que você investiga?"” (MIGNOLO, 2011, p. xxiv)

Logo, poderíamos investigar com mais rigor, por exemplo, questões teóricas particulares geradas pelos processos criativos de grupos teatrais brasileiros, que implicam na construção de discursos que incluem elementos de visualidade e plasticidade (imagem e materiais expressivos), sonoridade e corporeidade (ação e movimento, imagem, palavra e som), bem como de sentido lógico (discurso encadeado dos textos), além do uso do espaço e da relação construída entre o ator/performer e o espectador. Há, portanto, uma gramática que é construída pela cena, por meio do corpo do performer e do espectador, num acontecimento ao vivo.

Desse modo, pela diversidade de elementos, habilidades, dinâmicas e características do próprio acontecimento, pode-se notar que a performance cênica implica num saber bastante complexo. Além disso, conforme a teórica Fisher-Lichte (2008) notou, a performance (entendida aqui como fenômeno cênico - teatro, dança, performance art) possui um caráter de liminaridade, sendo um evento que acontece "entre" o espectador e o performer. Isso revela a performance como um lugar particularmente propício para processos de intercâmbio cultural, já que aproxima pessoas de diversos campos, religiões, condições socioeconômicas, gêneros, sexualidades, grupos étnicos, nações e culturas. Os processos de criação nas artes da cena podem ser pensados, portanto, como um laboratório para a vivência, o ensino e a aprendizagem de saberes outros, pela via do corpo, regidos por uma ética de respeito às diferenças.

2 No original: "It is from the body, not the mind, that questions arise and answers are explored. What calls for thinking is the body, rather than the mind"' (MIGNOLO, 2011, p. xxiv) 
Na procura por uma possível especificidade dos acontecimentos cênicos no Brasil, proponho a ideia de que esses são regidos por um hibridismo entre modos de produção cultural e artística. A mim parece que, em muitas produções espetaculares de grupos teatrais brasileiros há uma presença simultânea tanto da representação dramática quanto da brincadeira, presente nas manifestações e festas populares no Brasil.

As festas e as manifestações populares brasileiras são marcadas pela brincadeira com a ficção, sem a intenção de parecer real e sem a convenção da representação teatral, aliada à progressão dramática:

E que fique claro: isso não é representação, não está "no lugar de nada". É sim uma realidade de outra ordem. Esta outra ordem não é estranha às epistemologias do sul, acostumadas com a concomitância de planos: é Mateus - personagem do Cavalo Marinho - e é Seu Pedro, pescador que "brinca" com a ficção e tem com ela uma relação de duplo. Um exemplo da festa: Mateus (o "personagem") para Seu Pedro não é um ser ficcional, mas sim um outro nele, ou ainda, usando uma expressão de Bachelard, "um não-eu meu." Um exemplo da fé: Maria Padilha incorporada em Tânia, mulher comum, manicure do bairro. Entre a presença de Maria Padilha - a entidade - no corpo de mulher comum, para esta visão de mundo (ou para esta outra epistemologia), qual das duas é mais real? Você assiste a ambos e os vê dançar, falar. São eles e não são eles. Você vê através deles, além deles e muito mais. Qual teatro não deseja essa qualidade de presença? (FABRINI, 2013, p. 23)

A possibilidade de brincar de ser outro - e, concomitantemente, ser a si mesmo - permite uma breve suspensão do tempo cotidiano e dos papéis sociais assumidos. Age-se assim, no espaço liminóide, conforme termo de Turner (1990), estabelecendo o que esse teórico notou como correspondente a um estágio de reparação, ao refletir sobre as fases do drama social. Há também, a ocorrência da suspensão da descrença3, conceito construído na análise literária, que entende que o desejo de ouvir o fim de uma história ficcional leva um ouvinte ou leitor a suspender temporariamente a descrença de que aquilo não ocorreu na realidade. $O$ conceito parece aplicável às artes da cena e também à festa, já que sabe-se que o que é visto ou que se faz não corresponde a um papel social ou a uma ação da realidade cotidiana. $A$

3 Coleridge, citado por Sperber (2009, p. 455). No original: "willing suspension of disbelief". 
necessidade de criar ou a pulsão de ficção (SPERBER, 2009), inata a todos os seres humanos, pode explicar a familiaridade com o brinquedo ou a brincadeira das festas e manifestações populares, assim como o acionamento do "não-eu meu", dos planos notados por Fabrini (2003, p.23), levando a uma "realidade de outra ordem".

O conceito pulsão de ficção (SPERBER, 2009) indica que o ser humano possui uma necessidade inata de criar. Sua expressão e comunicação visam o entendimento do mundo ao redor, a elaboração de eventos vividos e emoções profundas. Ao colocar o corpo em ação ou tentar expressar-se por meio da linguagem falada, o indivíduo lida com "saberes básicos ou universais" "simbolização, efabulação e imaginário" (Ibid., p. 98). Se na infância aparecem jogos e o brincar, na idade adulta a criatividade se apresenta na relação com o cotidiano e o outro, bem como em atividades próximas ou efetivamente relacionadas ao fazer artístico. Dessa maneira, as linguagens e formas artísticas apresentam-se, como quer o referido conceito, como modos de superação do ser humano e consequente apaziguamento de sofrimentos vividos. Isso parece ser um dos propósitos por trás das brincadeiras e brinquedos nas festas e manifestações populares, nas quais o fantasiar-se, travestir-se, dançar, cantar e atuar ocorre simultaneamente a "ser fulano" ou "ser siclano", gerando uma aproximação convivial nas comunidades.

Considerar que a criação é uma necessidade inata, concordando com o conceito pulsão de ficção (Ibid.), permite reconhecer também a necessidade da alegria. Quando se pensa sobre aquilo que caracteriza uma cultura e que revela uma matriz geradora da sensação de pertencimento para os nascidos num determinado país, região e época, certamente vem à mente histórias contadas, vistas, representadas. Tais narrativas mostram desde os modos de pensar até o uso dos recursos da linguagem, as relações construídas por meio do imaginário, do simbólico e de eventos factuais que constituem a história de um lugar. A musicalidade da linguagem, o encadeamento de frases e o uso de determinado vocabulário estabelece uma rede, um tecido textual particular a cada cultura, que é certamente múltiplo e plural. O teatro e a dança indicam também a expressão de um povo, revelando as raízes, os indicadores de pertencimento, a influência e hibridismo com outras culturas, a 
emergência e singularidade de discursos próprios a um grupo de pessoas ou de caráter universalizante.

Na brincadeira da festa, a operação de conduzir o outro e de ser conduzido na via da ficção, de estender o ato de criar para todos os participantes mostra-se como uma ação potente que revela a alegria. Mesmo que se conte, dance ou represente uma história triste de lágrimas e sofrimentos, o desejo parece ser de transformação e de religar-se àquilo que se apresenta como um elemento formador da identidade cultural, ativo ou adormecido no indivíduo. A alegria talvez seja o sentimento que melhor expresse a ideia de bem-estar, de individualidade e de união ao outro. Se, conforme o ditado popular, "diante da dor, somos todos iguais", a alegria talvez expresse a possibilidade da diferença em um aspecto bastante positivo - aquilo que nutre a memória, que eleva o ser, que permite o não esquecimento e atua contra o silenciamento do sujeito, de povos e culturas. E que permite mesmo redimensionar o sofrimento, quando cômico e trágico se aproximam. O teatro, a dança e a festa talvez sejam, então, geradores potenciais de alegria.

Pergunto: como superar a colonialidade e suas marcas? Talvez a resposta já esteja dada, na própria cultura brasileira, que por meio da festa e da brincadeira, da fuga e da inteligência, tornou possível, por exemplo, a reocupação do lugar de rei pelo escravo africano, no Congado; a transgressão das normas, de gêneros e papéis sociais no Carnaval; o aparecimento do desafio no Cavalo Marinho, no repente e nas formas de histórias orais, chegando até a literatura de cordel. Se "rir é remédio santo", precisamos então de muitas doses de fic ção para sanar a ferida colonial ${ }^{4}$. A descolonização, a emergência de novos paradigmas de conhecimento e de existência, a ecologia de saberes $^{5}$, pode levar à operação de uma valorização da cultura brasileira a fim de extinguir um senso de inferioridade. Perceber, então, que nossas práticas, da rua ao teatro, nascem do corpo, do movimento, da fantasia, do convívio e

4 Segundo Mignolo (2005, p. xii), "Perspectivas a partir da colonialidade, no entanto, emergem das condições da "ferida colonial", o sentimento de inferioridade imposto sobre seres humanos que não se adequam ao modelo predeterminado nas narrativas euro-americanas"

5 As ecologias de saberes preconizam a " (...) ideia da diversidade epistemológica do mundo, o reconhecimento da existência de uma pluralidade de formas de conhecimento além do conhecimento científico". (Santos. In: SANTOS; MENESES, 2010, p. 54) 
geram histórias, nas quais não importa "quem me contou", o fato é que "me contaram" e... "foi assim, pronto e acabou".

\section{Referências bibliográficas}

CAFEZEIRO, E.; GADELHA, C. História do Teatro Brasileiro: de Anchieta a Nelson Rodrigues. Rio de Janeiro: UFRJ/EDUERJ/FUNARTE, 1996.

FABRINI, V. Sul da cena, sul do saber. Moringa - Artes do Espetáculo, João Pessoa, v. 4, n. 1, p. 11-25, jan./jun. 2013.

FISCHER-LICHTE, E. The transformative power of performance: a new aesthetics. London; New York: Routledge, 2008.

HALL, S. Da diáspora: identidades e mediações culturais. Belo Horizonte: UFMG, 2013.

MENCARELLI, F. A. Práticas corporais e alteridade na cultura de grupo: o Yuyachkani. In: ROCHA, M. A.; MEDEIROS, A. (Orgs.). Fronteiras e Alteridade: olhares sobre as artes na contemporaneidade. Belém, PA: PPGArtes UFPA, 2014.

MIGNOLO, W. D. Histórias locais/projetos globais: colonialidade, saberes subalternos e pensamento liminar. Belo Horizonte: UFMG, 2003.

. The idea of Latin America. Malden: Blackwell, 2005.

The darker side of Western modernity: global futures, decolonial options. Durham; London: Duke University Press, 2011.

SANTOS, B. de S. Between Prospero and Caliban: Colonialism, Postcolonialism, and Interidentity. Review (Fernand Braudel Center), v. 29, n. 2, p. 143-166, 2006.

(Org.). Conhecimento prudente para uma vida decente: um Discurso sobre as Ciências revisitado. São Paulo: Cortez, 2003.

-------. Do Pós-Moderno ao Pós-Colonial. E para além de um e de outro. Coimbra: 2004 (Conferência de abertura do VII Congresso Luso-Afro Brasileiro de Ciências Sociais). Disponível em: <http://www.ces.uc.pt/misc/Do_pos-moderno_ao_pos-colonial.pdf>.Acesso em: jan, 2016.

SANTOS, B. de S.; MENESES, M. P. (Orgs.). Epistemologias do Sul. São Paulo: Cortez, 2010.

A Non-occidentalist West?: Learned Ignorance and Ecology of Knowledge. Theory Culture Society, v. 26, n. 7-8, p. 103-125, 2009

(Org.). Reconhecer para libertar: os caminhos do cosmopolitismo multicultural. Rio de Janeiro: Civilização Brasileira, 2003.

SPERBER, S. F. Ficção e razão: uma retomada das formas simples. São Paulo: Hucitec/FAPESP, 2009.

SPIVAK, G. C. Pode o subalterno falar? Belo Horizonte: UFMG, 2010.

TURNER, V. Are there universals of performance in myth, ritual, and drama? In: 
SCHECHNER, R.; APPEL, W. By means of performance: intercultural studies of theatre and ritual. Cambridge, UK: Cambridge University Press, 1990. p. 8-18. WERNECK, M. H.; REIS, A. de C. (Orgs.). Rotas de teatro: entre Portugal e Brasil. Rio de Janeiro: 7 letras, 2012.

Recebido em 18/03/2016 Aprovado em 04/06/2016 Publicado em 01/07/2016 